\title{
Treating thalassemia major-related iron overload: the role of deferiprone
}

This article was published in the following Dove Press journal:

Journal of Blood Medicine

18 October 2012

Number of times this article has been viewed

\section{Vasilios Berdoukas' \\ Kallistheni Farmaki ${ }^{2}$ \\ Susan Carson' \\ John Wood ${ }^{3}$ \\ Thomas Coates'}

'Division of Hematology/Oncology, Children's Hospital Los Angeles, Los Angeles, CA, USA; ${ }^{2}$ Thalassemia Unit, General Hospital of Corinth, Corinth, Greece; ${ }^{3}$ Division of Cardiology, Children's Hospital Los Angeles, Los Angeles, CA, USA
Correspondence: Vasilios Berdoukas Division of Hematology/Oncology, Children's Hospital Los Angeles, 4650 Sunset Blvd,

Los Angeles, CA 90027, USA

$\mathrm{Tel}+\mathrm{I} 32336 \mid 2352$

$\mathrm{Fax}+13233613124$

Email vberdoukas@chla.usc.edu
Abstract: Over the last 20 years, management for thalassemia major has improved to the point where we predict that patients' life expectancy will approach that of the normal population. These outcomes result from safer blood transfusions, the availability of three iron chelators, new imaging techniques that allow specific organ assessment of the degree of iron overload, and improvement in the treatment of hepatitis. In October 2011, the Food and Drug Administration licensed deferiprone, further increasing the available choices for iron chelation in the US. The ability to prescribe any of the three chelators as well as their combinations has led to more effective reduction of total body iron. The ability to determine the amount of iron in the liver and heart by magnetic resonance imaging allows the prescription of the most appropriate chelation regime for patients and to reconsider what our aims with respect to total body iron should be. Recent evidence from Europe has shown that by normalizing iron stores not only are new morbidities prevented but also reversal of many complications such as cardiac failure, hypothyroidism, hypogonadism, impaired glucose tolerance, and type 2 diabetes can occur, improving survival and patients' quality of life. The most effective way to achieve normal iron stores seems to be with the combination of deferoxamine and deferiprone. Furthermore, outcomes should continue to improve in the future. Starting relative intensive chelation in younger children may prevent short stature and abnormal pubertal maturation as well as other iron-related morbidities. Also, further information should become available on the use of other combinations in chelation treatment, some of which have been used only in a very limited fashion to date. All these advances in management require absolute cooperation and understanding of parents, children, and, subsequently, the patients themselves. Only with such cooperation can normal long-term survival be achieved, as adherence to treatment is now likely the primary barrier to longevity. Keywords: thalassemia, iron overload, iron chelation therapy, magnetic resonance imaging, deferoxamine, deferiprone, deferasirox

\section{Introduction}

Regular blood transfusions and iron chelation therapy are standard treatment for thalassemia major. The repeated transfusions gradually increase the total body iron load, resulting in secondary hemosiderosis with complications in the heart, endocrine glands, and liver. The introduction of iron chelation with deferoxamine (DFO), although parenteral, significantly improved survival. ${ }^{1}$ However, cardiomyopathy remained the most common and important cause of death, and endocrine morbidities became very common in long-term survivors. ${ }^{2}$ Poor treatment compliance with DFO was associated with early onset of cardiac complications and morbidities. Serious problems also arose in patients who, according to their regular evaluations with ferritin and liver iron 
concentration, were considered to be compliant and to have acceptable levels of iron load. ${ }^{3}$ The successive addition of deferiprone (DFP) in Europe in 1999 and deferasirox (DFX) in 2006 offered the advantage of iron chelation that could be orally administered. With the licensing of DFP in the US in October 2011, new options are becoming available for optimal prescription of iron chelation in American patients. Today, the chelation options available are monotherapy with any of the three iron chelators DFO, DFP, or DFX. Currently, the three drugs are licensed for monotherapy. However, combinations of any two of them or even all three provide newer and more effective choices for patients and their physicians. What should be offered to each patient with respect to iron chelation can now be determined by newer and better methods for the estimation of total body iron load as well as the degree of hemosiderosis of individual organs such as the heart, ${ }^{4}$ liver, ${ }^{5,6}$ pituitary, ${ }^{7,8}$ and pancreas $^{9}$ by magnetic resonance imaging (MRI). Methods are being developed to assess "free" iron, the iron that is not bound to transferrin in the circulation or is free within cells and not attached to ferritin. This iron can cause tissue damage and may be detected by specific assays. ${ }^{10,11}$ With the knowledge obtained by these evaluations, the appropriate chelation regime can be tailored to the individual needs of each patient. As shown over the last 10 years in a number of European studies, early intervention with intensification of iron chelation, where appropriate, has allowed the reduction of life-threatening iron overload with reduced mortality from cardiac causes. ${ }^{12,13}$ Such interventions have also reduced morbidities related to endocrinopathies. ${ }^{14}$

\section{The evaluation of iron burden}

The evaluation of the iron burden is essential for the determination of clinical outcomes, deciding when to commence chelation, selection of the regime that should be prescribed, the continuous monitoring of chelation efficacy, and the fine-tuning of the regime. Important parameters include the history of transfusions, type of chelation, and the patient's compliance to treatment. In general, patients are loaded with iron at an average rate of $0.5 \mathrm{mg} / \mathrm{kg}$ body weight (bw)/day with a range between $0.32 \mathrm{mg} / \mathrm{kg}$ and $0.64 \mathrm{mg} / \mathrm{kg} .{ }^{15}$ Ferritin has been the relatively universally available method for assessment of iron stores. The recent availability of MRI technology to permit noninvasive evaluation of the concentration of iron in the liver (liver iron concentration [LIC]), heart, and other organs permits direct monitoring of tissue iron. Recently, the assessment of nontransferrin-bound iron (NTBI), a part of which is labile plasma iron (LPI), has become available, ${ }^{16}$ and further evaluation of its potential value is being investigated. LPI may prove to be a valuable adjunct to the evaluation of a patient's status.

\section{Ferritin}

Ferritin is a metalloprotein that is found in cells. It stores and releases iron in a controlled manner. In normal individuals, a small amount appears in the circulation and in general reflects the degree of total body iron. Normal values of serum ferritin for men and women are $12-300 \mathrm{ng} / \mathrm{mL}$ and 12-150 ng/mL, respectively. Thalassemia patients with ferritin values that are consistently $<1000 \mathrm{ng} / \mathrm{mL}$ have a better prognosis. ${ }^{2}$ Ferritin is an acute phase reactant, and the serum levels may be disproportionately greater than the degree of iron loading in infections, inflammatory states, liver dysfunction, and malignancies. Conversely, it is low in the presence of vitamin $\mathrm{C}$ deficiency. Despite its limitations, ferritin remains an easy, economical, and widely used indicator for assessing iron load. The continuous monitoring of ferritin values in individual patients reflects trends of body iron burden, the effectiveness of and adherence to iron chelation therapy, and its impact on mortality and morbidity. However, in a recent analysis of our data comparing LIC to ferritin we have found that over certain periods of time, even up to 4 years, the trends in ferritin can be opposite in direction to the change in total body iron as derived from $\mathrm{LIC}^{17}$ or disproportionate to the changes in LIC. This could lead to inappropriate changes in therapy and incorrect assumptions by health care providers about patient adherence. It is accepted that poor compliance with chelation therapy is the greatest barrier to effective management of iron overload. If only ferritin is used to assess total body iron, a number of patients could be discouraged by their apparent poor response to therapy, even though their LIC may be decreasing. Knowledge of LIC in addition to ferritin is essential so that errors in clinical decisions and patient frustration can be avoided. The confidence intervals between any serum ferritin and total body iron stores is quite large, making ferritin primarily useful in evaluating groups of patients rather than individuals.

\section{Labile plasma iron}

NTBI species appear when the iron binding capacity of transferrin is exceeded. When the transferrin saturation is over $70 \%-80 \%$, LPI appears. ${ }^{18-21}$ The LPI represents a component of NTBI that is both redox active and chelatable and capable of permeating organs. Sustained elevated 
levels of LPI could, over time, compromise organ function and decrease patient survival. Measurements of LPI may provide an indication for the presence of forms of iron that can lead to tissue iron overload. It may be a more reliable marker of the iron status at one particular time point than ferritin, as the latter is a longer-term index of iron load. If LPI levels are maintained at low or normal levels $(0.2-0.5 \mu \mathrm{mol} / \mathrm{L})$, it is thought that tissue damage from the free iron may be prevented. Further studies with the measurement of LPI may provide a convenient and immediate index of when to start chelation, chelation efficacy, adequacy of doses of chelator prescribed, and patient compliance. ${ }^{21}$

\section{Liver iron}

In transfusion-dependent patients, the iron in the liver represents the total body iron load, as it stores $70 \%-80 \%$ of the iron. ${ }^{22}$ The normal level is $<0.8 \mathrm{mg} / \mathrm{g}$ dry weight (dw), but up to $1.5 \mathrm{mg} / \mathrm{g} \mathrm{dw}$ is acceptable. Today, liver biopsy has been replaced by noninvasive methods of evaluation, of which the most important and internationally widely used is MRI. ${ }^{5,6}$ Superconducting quantum interference device susceptometry is also a useful noninvasive method for evaluating LIC, but its value is limited by the small number of machines available worldwide. ${ }^{23}$ In general, liver MRI should be repeated on an annual basis. In the past, levels of LIC $<7 \mathrm{mg} / \mathrm{g} \mathrm{dw}$ were considered indicative of mild iron loading and were regarded as satisfactory, between $7 \mathrm{mg} / \mathrm{g} \mathrm{dw}$ and $12 \mathrm{mg} / \mathrm{g} \mathrm{dw}$ as moderate, and $>12 \mathrm{mg} / \mathrm{g}$ $\mathrm{dw}$ as heavy. ${ }^{24}$ For reasons explained here, it now seems important to aim for normal LIC. Patients with high levels of LIC were at increased risk of developing cardiac iron compared with patients with low LIC. ${ }^{25}$ Although low levels of LIC were generally associated with a better prognosis, some patients developed cardiac dysfunction as a result of increased cardiac iron, despite disproportionately low levels of LIC. ${ }^{3,26}$ Studies with MRI confirmed the lack of a clinically useful relationship between the cardiac and hepatic iron. ${ }^{27,28}$ Figure 1 demonstrates the findings in the study from Aessopos et $\mathrm{al}^{27}$ with respect to the LIC and the cardiac $\mathrm{T} 2 *$ in patients who had been on DFO therapy. It clearly shows that in patients with LIC $<7 \mathrm{mg} / \mathrm{g} \mathrm{dw}$ a significant number have excessive cardiac iron, and some patients with LIC $>7 \mathrm{mg} / \mathrm{g}$ dw do not have cardiac iron. Knowledge of LIC is very important; particularly in the presence of active hepatitis $\mathrm{C}$ infection, as excess iron increases the risk of fibrosis, ${ }^{22}$ cirrhosis, and liver cancer. $^{29}$

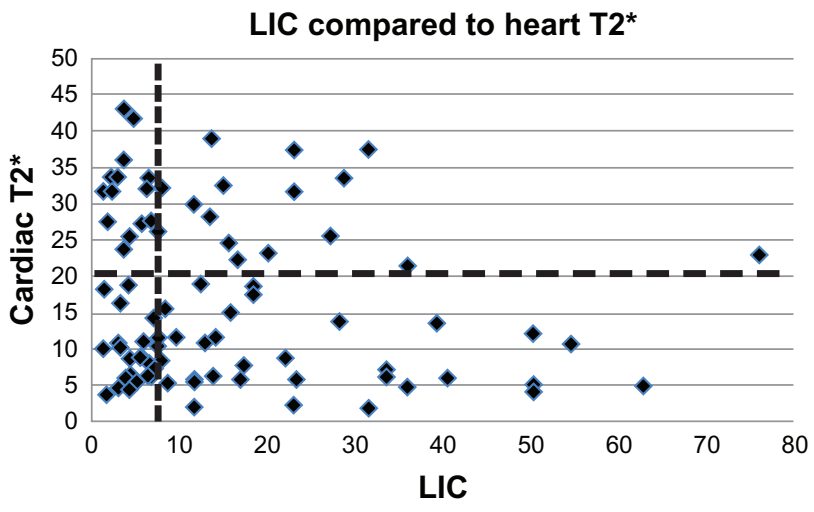

Figure I Showing the liver iron concentration (LIC) compared to cardiac T2*. The horizontal line is the level above which the heart is thought not to be excessively iron loaded. The vertical line indicates the LIC value of $7 \mathrm{mg} / \mathrm{g} \mathrm{dw}$.

\section{Cardiac iron}

The estimation of cardiac iron by MRI with T2* was developed in the Brompton Hospital, London, UK. The method is simple, accurate, and reproducible. ${ }^{4}$ It was also instituted at the Children's Hospital of Los Angeles, Los Angeles, CA, ${ }^{30}$ and is now used in many international centers. The technology confirmed suspicions that the LIC had little predictive value on the degree of cardiac iron load and the risk of cardiac dysfunction. A low cardiac T2* indicates high cardiac iron. Although total body iron as measured by LIC does not permit estimation of cardiac iron, the presence of cardiac iron (low $\mathrm{T} 2 *$ ) is generally seen in patients with high degrees of total iron loading. Over the past decade, common usage has been to express LIC in $\mathrm{mg} \mathrm{Fe} / \mathrm{gm}$ dw of liver, and cardiac iron in terms of $\mathrm{T} 2 *$ in milliseconds $(\mathrm{ms}) .{ }^{6}$ Thus, the cardiac $\mathrm{T} 2 *$ is inversely correlated with degree of cardiac iron loading. A study on hearts from deceased or cardiac-transplanted patients has shown that the MRI-derived formula $[\mathrm{Fe}]=45(\mathrm{~T} 2 *)^{-1.22}$ can be used to express the amount of iron in the heart in $\mathrm{mg} / \mathrm{g}$ $\mathrm{dw},{ }^{31}$ in a similar fashion to the liver. With this calculation a T2* of $5 \mathrm{~ms}$ corresponds to a cardiac iron concentration of $6.3 \mathrm{mg} / \mathrm{g} \mathrm{dw}$. This was the mean level at which death from cardiac causes occurred in patients whose hearts were donated for that study. An LIC of $6.3 \mathrm{gm} / \mathrm{g} \mathrm{dw}$ would not be alarming, and, in the past, levels $<7 \mathrm{gm} / \mathrm{g} \mathrm{dw}$ were thought to be quite satisfactory. This demonstrates the differential sensitivity of the heart compared with the liver to iron damage There is a correlation between $\mathrm{T} 2 *$ and left ventricular ejection fraction (LVEF). Decreased LVEF is associated with low values of $2 *$. The probability of impaired cardiac function increases when the T2* value is $<20 \mathrm{~ms}(1.2 \mathrm{mg} / \mathrm{g} \mathrm{dw})$. Patients on DFO alone with $\mathrm{T} 2 *$ values $<10 \mathrm{~ms}$ have a $>50 \%$ chance of developing heart failure in the ensuing 12 months if their chelation regime is not changed. ${ }^{32}$ 


\section{Iron load of other organs}

Early detection of endocrinopathies is imperative, as most patients are likely to be asymptomatic at early stages, and with the use of appropriate chelation regimes and normalization of LIC levels endocrinopathies may be reversible. Regular clinical evaluation of patients with height, including sitting height, length of long bones, weight, and pubertal staging assists in determining whether transfusions and chelation therapy are adequate and whether there could be growth delay related to the chelator prescribed. Dynamic tests and hormonal assessment are used to detect iron overload in peripheral glands. For glucose metabolism abnormalities, an oral glucose tolerance test is performed together with insulin measurements. For thyroid function, free T4, thyroid-stimulating hormone, and thyrotropinreleasing hormone tests are undertaken in order to differentiate primary from secondary hypothyroidism. For hypogonadism, sex hormones and a gonadotropin-releasing hormone test are used. After the second or third decade of life and in heavy iron-overloaded patients, the anterior pituitary might also be damaged, and regulatory hormonal secretion (luteinizing hormone, follicle-stimulating hormone, thyrotropin-releasing hormone) may be disrupted. MRI may then reveal a reduced volume and excess pituitary iron. ${ }^{7,833,34}$ Also, the degree of the pancreatic iron overload evaluated by MRI was related to glucose metabolism ${ }^{9,35,36}$ and, moreover, may herald the onset of cardiac siderosis. However, there is no absolute relationship of glucose metabolism disorders to the degree of iron loading present in the pancreas. The absence of pancreatic iron is highly predictive of normal cardiac iron, and the presence of pancreatic iron suggests that cardiac iron loading may be imminent. ${ }^{35,37,38}$ A recent publication from Corinth in Greece has shown that if iron levels can be brought to normal with LIC $<1 \mathrm{mg} / \mathrm{g}$ dw and ferritin $<100 \mathrm{ng} / \mathrm{mL}$, there is a significant possibility that there may be a reversal of endocrinopathies. ${ }^{14}$ There was no increase in adverse events associated with the achievement of such low ferritin levels or new unexpected adverse events. Other centers are reporting low ferritin levels, and it would seem necessary to monitor patients very carefully for side effects when such low levels or iron load are achieved.

\section{Clinical assessment of iron load}

At each clinic visit it is important to inquire about general well-being, whether the patients have had any serious problems, their school or employment performance, and how they have managed their chelation therapy since last seen. Where appropriate, libido and satisfaction with sexual activity need to be evaluated. Clinically, skin color should be assessed, and if the patients have been prescribed DFO, the sites of infusion need to be inspected for an evaluation of compliance, including how recently an infusion was administered. Regular evaluations of ferritin and liver function tests at each transfusion, LIC, cardiac evaluation with electrocardiogram and echocardiography, and biochemical evaluation of endocrine function should be performed at least annually. It is important to note that the clinical parameters and the degree of siderosis of the different organs do not always show an expected relationship. For example, some patients with excess cardiac iron may have excellent cardiac function, and a patient with only mild pancreatic iron overload may be diabetic.

\section{The iron chelators Deferoxamine}

DFO binds iron in a 1:1 ratio. Approximately $50 \%$ of the DFO:Fe complex (ferrioxamine) is excreted in the urine and the remainder in the feces. However, this ratio is very variable, and a urine analysis of the amount excreted cannot be relied upon to provide accurate estimations of the total iron excretion in response to a dose of the medication. Because it is not orally absorbed and it has a very short half-life, the most common form of administration is by slow subcutaneous infusion by small portable pumps. ${ }^{39,40}$ Slow infusion is critical. Rapid infusion of DFO results in rapid excretion of drug unbound to $\mathrm{Fe}$ and significant loss of chelation efficiency. The usual dose for children is $20-40 \mathrm{mg} / \mathrm{kg} \mathrm{bw} /$ infusion and for adults is $50-60 \mathrm{mg} / \mathrm{kg}$ bw/infusion 5-7 days a week depending on the degree of iron load. ${ }^{41}$ Although many centers give the drug 5-7 days a week, it is best to give it 7 days a week. This is especially true if there is significant elevation of the LIC $(>7 \mathrm{mg} / \mathrm{g}$ $\mathrm{dw}$ ) or cardiac iron loading. ${ }^{42}$ Any time the chelator is not circulating, NTBI is free to load the heart and endocrine organs. The infusions are usually given at night while the patient sleeps and over an 8-12 hour period. DFO was able to maintain LIC at levels that were acceptable for the time, and in many cases maintained heart function. ${ }^{43,44}$ Survival improved with its use, ${ }^{45}$ but cardiac complications remained the main cause of premature death during the latter half of the 20th century. ${ }^{2,26}$ With the advent of MRI, a large proportion of patients who were receiving DFO demonstrated significant cardiac iron overload, and a significant number of those had cardiac iron at potentially dangerous levels..$^{27,28}$ In patients with severe heart failure and very heavy cardiac iron load, DFO was administered intravenously in larger doses up to $100 \mathrm{mg} / \mathrm{kg}$ bw/day, usually by 24 hour/day continuous infusion. This approach resulted in satisfactory outcomes in most cases. ${ }^{46,47}$ The most common and most 
frequent adverse complications associated with its use are local topical reactions. General reactions, growth delay, ${ }^{48}$ bony abnormalities, ${ }^{49}$ impaired hearing, ${ }^{50}$ and visual disturbance ${ }^{51}$ are less common and have been associated with disproportionately high doses of medication compared with the degree of the patient's total body iron load. Infection with the bacteria Yersinia and Klebsiella are more common in individuals who have excess body iron. However, during treatment with DFO, the risk of infections with these microorganisms is increased and represents the most dangerous risk associated with DFO use. ${ }^{52-56}$ Physicians must be vigilant for symptoms that may indicate infections from either of these organisms.

\section{Deferiprone}

DFP is a chelating agent that is administered orally. It binds iron in a 3:1 ratio. The majority of the DFP iron complex is excreted in the urine (about 90\%) and the remainder in the feces. It is available in Europe as tablets and syrup. At present, only the tablet form has been approved for use in the US. The dose approved by the Food and Drug Administration is $75-99 \mathrm{mg} / \mathrm{kg}$ bw/24 hours, and because of its very short half-life it should be given in three divided doses, usually approximately 8 hours apart. It is equally as effective as DFO in its ability to remove liver iron. ${ }^{57-59}$ It is particularly effective in removing iron from the heart. ${ }^{26,60,61}$ In a number of studies it has shown improvement in the LVEF, ${ }^{60}$ and in a recent study improvement in the right ventricular ejection fraction. ${ }^{62}$ A large multicenter study in Italy demonstrated significant cardioprotective effects with its use. ${ }^{63}$ The beneficial effects of DFP are thought to be related to its low

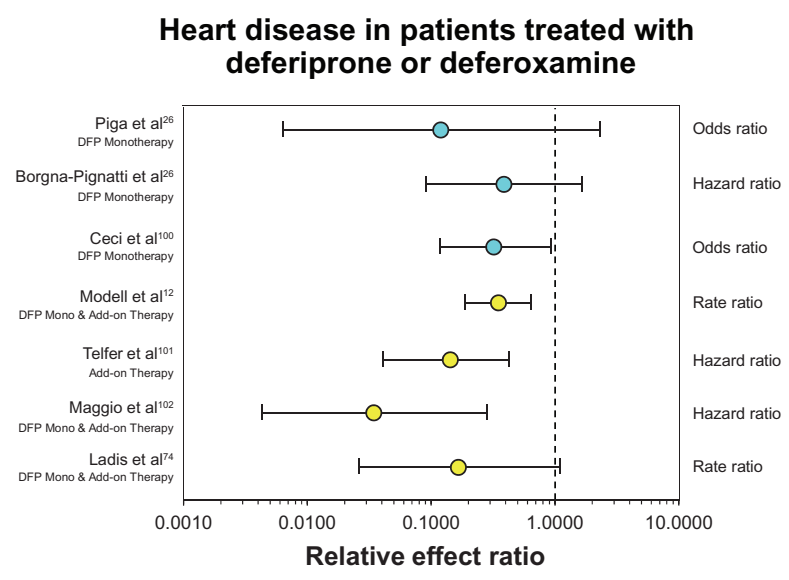

Figure 2 Showing a forest plot indicating the odds ratio or hazard ratio for a patient to develop cardiac disease when taking deferiprone, either as monotherapy (blue circles) or in combination with deferoxamine (yellow circles), compared with taking defoxamine alone (vertical dotted line). molecular weight and its increased membrane permeability. This capability allows it to pass the blood-brain barrier and may be responsible for the increased efficacy on the pituitary endocrine axis. In addition, it has the unique property of redistributing iron within cells and cellular organelles. One of the components of iron within the cells is labile cellular iron. DFP, with its rapid access and low molecular weight, may chelate this iron and reduce its toxic potential. ${ }^{64}$ It is this action that is thought to improve mitochondrial function in the heart ${ }^{65}$ and the endocrine glands. ${ }^{66}$ A recent presentation to the Food and Drug Administration included information shown in Figure 2, indicating that regardless of the rigor of the study design, the method of analysis, or the statistical evaluation, the same trend was observed for lower risk of heart disease or death in patients treated with DFP either as monotherapy or in combination with DFO ${ }^{67}$ The most serious side effect associated with its use is agranulocytosis, which occurs in $<2 \%$ of patients. ${ }^{68}$ Agranulocytosis can be life threatening. Therefore, close monitoring of absolute white cell counts at between 5 and 10 daily intervals is recommended, and education of the patients regarding the possibility of this complication as well as clear guidelines about symptoms and problems they may encounter is essential. Other adverse effects associated with its use include neutropenia, which may precede agranulocytosis, arthralgias, gastrointestinal disorders, weight gain, and increased liver enzymes. ${ }^{68}$ The increased liver enzymes usually occur in the first few months of treatment and usually return to pre-DFP levels within approximately 6 months. Note that liver enzymes may be three to five times normal because of iron-induced hepatitis. This will correct as iron is removed from the liver. The arthralgias and gastrointestinal disturbances can be managed by a reduction in dose with a slow increase to the required dose once the symptoms have settled. It is rare that the medication needs to be ceased for these side effects. If agranulocytosis occurs, it is recommended that the patient not be re-challenged with the drug unless there is a significant specific benefit with its use compared with other chelators.

\section{Combined therapy with deferoxamine and deferiprone}

It is postulated that the combination of DFO and DFP (DFODFP) has a shuttle effect with DFP donating iron to DFO, and it does have at least an additive effect on iron excretion. ${ }^{69}$ The combination was found to be very effective at reducing ferritin. ${ }^{70}$ All patients on DFO-DFP achieved negative iron balance, even with administration of DFO only 3 days a week and DFP daily. ${ }^{69}$ Combined therapy means that DFP is taken 
every day and DFO 1-7 days per week depending on clinical concern and degree of iron burden. A randomized controlled study from Sardinia showed that DFO-DFP significantly reduces cardiac and hepatic iron. ${ }^{71}$ Furthermore, patients with very heavy cardiac iron overload $(\mathrm{T} 2 *<8 \mathrm{~ms}$ with a mean of $5 \mathrm{~ms}$ ) showed a marked improvement in their T2* value (mean increase by $3 \mathrm{~ms}$ ) and marked improvement in their $\mathrm{LVEF}^{72}$ when treated with DFO-DFP. An observational study in which patients had between two and six MRI studies with at least 12 months between each study over a 7-year period, and in which the annual change in cardiac and hepatic iron was evaluated, demonstrated that DFP and DFO-DFP were better at reducing cardiac iron, particularly in the heavier ranges of iron load, than DFO or DFX as monotherapy. ${ }^{73} \mathrm{~A}$ cross-sectional observational study from Athens, Greece, reported a reduction in cardiac-related deaths from 7.9 per 1000 patient-years with monotherapy with DFO compared with 2.3 per 1000 patient-years with the use of DFP alone or DFO-DFP. ${ }^{74}$ Also, there are many case reports that demonstrate reversal of end-stage acute heart failure with the use of DFO-DFP. ${ }^{75-77}$ The aforementioned improvement in endocrinopathies was achieved only with the use of DFODFP. ${ }^{14}$ Specifically, $64 \%$ of diabetes type 2 patients, $63 \%$ with impaired glucose tolerance, and $100 \%$ of those with impaired fasting glucose reversed. Fifty percent of hypogonadal males were able to cease testosterone replacement therapy. In the hypogonadal females, $32 \%$ gave birth to six children, two of whom by normal conception. Fifty-six percent of patients were able to stop thyroxin replacement therapy. A patient of one of the authors demonstrated an improvement in her glucose tolerance when her liver iron normalized. When her

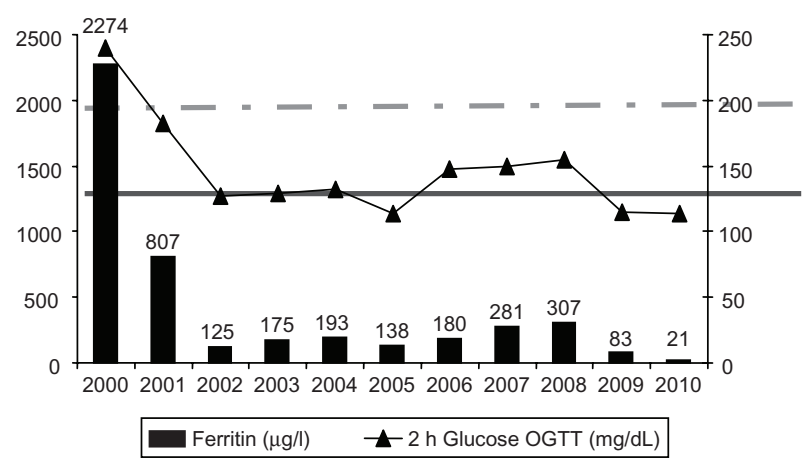

Figure 3 Improvement in glucose metabolism with reduction in ferritin after intensive chelation with the combination of deferoxamine and deferiprone.

Notes: In 2006-2008, compliance deteriorated and with only a slight increase in ferritin and liver iron concentration, glucose metabolism deteriorated. Once compliance improved, glucose metabolism normalized. The bold line is the level below which the 2-hour glucose level is acceptable, and the broken line is the level above which it is considered that a patient is diabetic. The area between is regarded as impaired glucose tolerance.

Abbreviation: OGTT, oral glucose tolerance test. compliance reduced and her ferritin increased to only 300 $\mathrm{ng} / \mathrm{mL}$, her glucose tolerance deteriorated. Subsequently, when her compliance improved again and her ferritin fell to $30 \mathrm{ng} / \mathrm{mL}$, her glucose tolerance normalized again (Figure 3). There were no changes in the frequency or nature of adverse events in patients taking DFO-DFP compared with those with either medication as monotherapy. Of note, with very low levels of iron load, DFP shows no toxic effects. As this combination treatment involves subcutaneous infusions, which are burdensome for the patients, it may be prescribed until the LIC and cardiac iron concentrations are at satisfactory levels, after which further tailoring of appropriate chelation can be prescribed.

\section{Deferasirox}

The oral chelator DFX binds to iron in a $2: 1$ ratio. The complex is excreted almost exclusively in the feces. It is provided as tablets that form a suspension in liquid. Due to the relatively long half-life, it may be administered in a once-daily dose, ranging between $10 \mathrm{mg} / \mathrm{kg}$ bw and $40 \mathrm{mg} / \mathrm{kg}$ bw. The ease of administration offers great advantage to improving compliance, which is of utmost importance in situations where therapy needs to be taken on a long-term basis. The efficacy of DFX is dose dependent. The development of this chelator involved well-planned and vast clinical trials, leading to many studies that showed the effectiveness of DFX in decreasing ferritin and LIC. ${ }^{78-83}$ Three recent prospective studies have shown that DFX is effective in removing iron from the heart (increase in cardiac T2*), although the LVEF remained unchanged. ${ }^{84,85}$ In one of these studies, the reduction in cardiac iron was observed mainly in patients with mild to moderate liver siderosis. ${ }^{86} \mathrm{DFX}$ did not reduce the iron in the heart of patients who had excessive liver iron overload (usually $>30 \mathrm{mg} / \mathrm{g} \mathrm{dw}$ ). There was no increase in heart iron in the patients who did not have excessive cardiac iron at baseline. This group showed a small increase in LVEF. ${ }^{87}$ The most serious side effect of DFX is decreased renal function, as indicated by a decrease in creatinine clearance to $<40 \mathrm{~mL} / \mathrm{min}$, albuminuria, or increase in serum creatinine $>33 \%$ above baseline values or above the upper age-related normal range. Other common side effects are gastrointestinal disorders and rash. Increases in hepatic enzymes requiring cessation of the drug occurred in $<5 \%$ of patients. Rare side effects are anaphylactic reactions, cytopenias, Fanconi type nephrotic syndrome, gastrointestinal ulceration and hemorrhage, impaired hearing, and ophthalmological problems. Regular monitoring and questioning of patients for such effects are necessary. ${ }^{88}$ 


\section{Deferasirox and deferoxamine in combination}

There has been a report on the use of DFX and DFO sequentially in patients in whom there were concerns about excessive iron hepatic overload ${ }^{89}$ All of the patients showed a decrease in serum ferritin without any side effects. The protocol, combining DFX and DFO in sequence, was effective and safe. A study with combined use of DFX daily and DFO 3-7 days per week suggested that simultaneous administration was well tolerated and had low potential for toxicity. From these preliminary data, this combination seemed to be effective in lowering body iron in high-risk patients. ${ }^{90}$

\section{New opportunities for chelation}

With the licensing of DFP in the US, it is now reasonable to consider the use of DFP in combination with DFX. The use of two oral chelators is more acceptable to patients than one oral and the other injectable. Prior to the licensing of DFP, we were able to use DFP on compassionate grounds for patients with thalassemia major or sickle cell anemia on regular transfusions. Our indication for its use was excessive cardiac iron load (T2* $<10 \mathrm{~ms}$ ). For this reason, in all the patients who were treated with DFP, we prescribed it in combination with DFX. In one patient we prescribed all three chelators. Table 1 shows the MRI outcomes in our patients and the period of time during which they were prescribed the combination. Unfortunately, not all these patients were very compliant, particularly to their DFX medication. Because of this, the LIC reduced in only two patients, increased in three, and remained more or less unchanged in two. The best improvement was seen in the patients who were on this combination for 7 years. The LVEF did not seem to improve, though T2* increased (improved) even in the poorly compliant patients. A group of 16 patients from Corinth in Greece were prescribed combination therapy of DFX and DFP because of the presence of more than one iron overload complication or because of refusal to use $\mathrm{DFO}^{91}$ or concern about DFO-mediated toxicity in the presence of low levels or iron load. This 2-year study showed encouraging results with respect to LIC, even though the patients' baseline mean LIC was very low. Most importantly, they demonstrated a significant increase in the mean $\operatorname{LVEF}(P=0.0014)$ in all patients and a reversal of cardiac complications in three of them, but also an improvement of glucose metabolism, as shown by the reduction in the area under the curve for glucose during an oral glucose tolerance test. Additionally, the protocol was beneficial with respect to gonadal function. With the licensing now of DFP in the US, it is likely that more patients

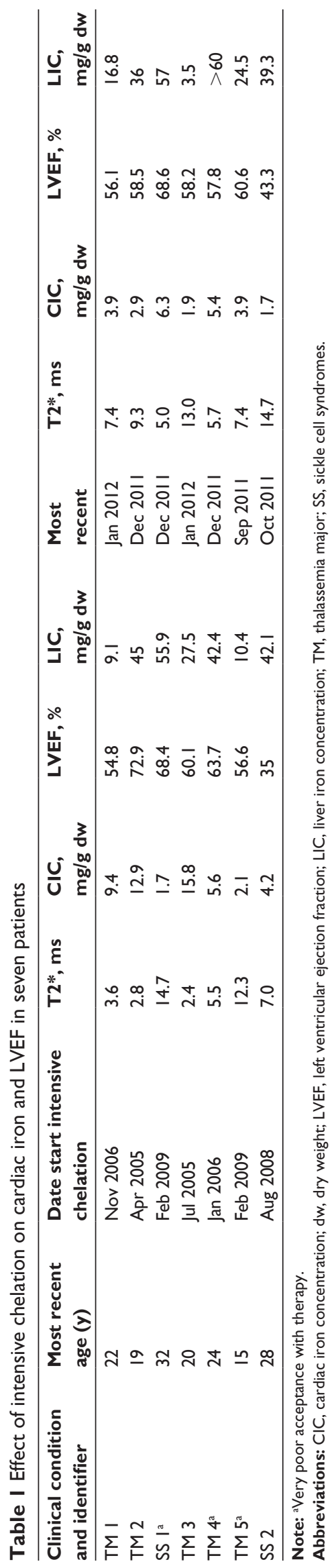


will be offered this combination, particularly where there are concerns about the degree of iron loading, be it in the heart, liver, pituitary, or pancreas. Overall, the results are very encouraging, and further results with respect to safety and efficacy are necessary before it can be considered standard therapy. ${ }^{92,93}$

\section{Re-evaluation of the goals of iron chelation therapy}

It is now recognized that it is most important to have the continuous presence of a chelating agent in patients' circulation in order to reduce the amount of free iron in plasma (LPI), to prevent its entry into cells, and to protect from the oxidant radicals that are principally responsible for tissue and organ damage. ${ }^{94-97}$ The question arises of the value of increasing the LVEF from normal levels to even more normal levels. A recent publication on patients with thalassemia who had participated in two studies mentioned previously and who showed improvement in their LVEF reduced their risk of developing cardiac failure according to how much their LVEF increased. It is now being postulated that these improvements may be related to the reduced burden of the free iron on the mitochondria within the cardiac muscle cells, allowing rapid improvement disproportionate to the slow reduction in the cardiac iron load..$^{98}$ Therefore, the use of medications that improve LVEF is preferable. We have known for some time that iron cardiomyopathy is reversible if treatment is started before the patient is severely symptomatic. It is also clear that reducing LIC levels certainly to $<18 \mathrm{mg} / \mathrm{g}$ and probably $<8 \mathrm{mg} / \mathrm{g}$ facilitates removal of cardiac iron. ${ }^{99}$ Although reversal of endocrine dysfunction is not so certain, the recent success in reversing some endocrinopathies by normalizing LIC suggests that much lower LIC levels must be obtained to reverse endocrine dysfunction. Thus, to improve and prevent complications of hemosiderosis, it seems that the aim of chelation therapy should be to maintain the iron load at normal levels, as indicated by an LIC of $0.8-1.5 \mathrm{mg} / \mathrm{g} \mathrm{dw}$. This level of chelation can be safely attempted only if reliable measures of LIC are routinely available. The issue of when to start chelation and how aggressive the chelation should be requires ongoing evaluation. If started at an appropriate time and total body iron is maintained at close to normal levels, with ongoing evaluation of tissue-specific iron load, it would seem likely that morbidities such as endocrinopathies may be avoided.

\section{Future research on chelation}

We now have three chelators that are very effective. They have different toxicities and different organ specificity. The recognized overwhelming barrier to efficacy of chelation is the impact that chronic iron overload and the need to take daily medications has on quality of life and ability of patients to adhere to prescribed treatments. None of these drugs work if they are not taken. It seems clear from anecdotal reports that combinations of these medications are much more effective than monotherapy. Although it would be optimal to have nicely designed combination therapy comparison trials to determine efficacy and toxicity, it would take a Herculean effort and massive amounts of money, and still the results would likely be biased and dominated by patient adherence. One of the great advantages of having three drugs is the ability to use combinations to tailor treatment to the individual's lifestyle so they at least have some chelator every day. We would propose that the large sums of money required for a combination trial would be best spent looking for new, more effective agents, and that a well-designed international cooperative registry be set up to monitor toxicity and efficacy of combinations. In addition, research on compliance to chelation and how this might be optimized and a greater understanding of the different sensitivities of various organs to excess iron will assist in the approaches to chelation therapy that would further improve survival and reduce morbidities.

\section{Key points in iron chelation therapy and thalassemia major}

Until recently, cardiac complications were the leading cause of death in European thalassemia patients, and remain the most common cause of death in North American patients.

MRI can detect the degree of risk of cardiac dysfunction that patients run according to their cardiac iron estimation.

Measurement of ferritin alone can be misleading in monitoring total body iron and optimally should be used in conjunction with direct measurement of LIC.

Assessment of LPI, which recently became available, may be a valuable adjunct to the evaluation of patients' iron load status.

Intensification of patients' chelation regime is essential in those with a significant risk of developing cardiac dysfunction. To date, most of the information available indicates that the best regime to this effect is combination therapy with DFP and DFO. It has been demonstrated to reduce the risk of heart failure relatively rapidly.

Heart failure from hemosiderosis can be reversed by intensification of iron chelation.

To prevent and reverse cardiac and endocrine organ loading with iron, and to maximize protection from iron-induced 
oxidant damage, it is important that patients have some chelator circulating every day. This is especially important if the LIC is significantly elevated $(>7 \mathrm{mg} / \mathrm{g} \mathrm{dw})$.

Although the incidence of endocrinopathies reduced with the use of DFO, it still remains a significant and frequent complication. The reversal and prevention of endocrinopathies may be effected by very intensive chelation with DFO-DFP or DFP-DFX with the intent to normalize the LIC.

Regardless of what we can achieve in clinical studies, patients' compliance defines long-term disease-free survival.

Further studies on the safety and efficacy of different combinations are necessary to determine how low total body iron may be reduced and whether such low levels can prevent or reverse morbidities in most patients.

\section{Declaration}

VB is a consultant to ApoPharma Inc, and has a confidentiality agreement with Novartis Inc. KF has no conflicts to declare. $\mathrm{SC}$ is on the Speakers Bureau for Novartis Pharmaceuticals. JW has research funding from Novartis and consults for Novartis, ApoPharma, and Ferrokin Biosciences. TC has received consulting fees from Novartis, Sangart Inc, and ApoPharma and has served on Speakers Bureau for Novartis and Adventrix Pharmaceuticals Inc.

\section{References}

1. Ladis V, Chouliaras G, Berdousi H, Kanavakis E, Kattamis C. Longitudinal study of survival and causes of death in patients with thalassemia major in Greece. Ann NY Acad Sci. 2005;1054:445-450.

2. Borgna-Pignatti C, Rugolotto S, De Stefano P, et al. Survival and complications in patients with thalassemia major treated with transfusion and deferoxamine. Haematologica. 2004;89(10):1187-1193.

3. Berdoukas V, Dakin C, Freema A, Fraser I, Aessopos A, Bohane T. Lack of correlation between iron overload cardiac dysfunction and needle liver biopsy iron concentration. Haematologica. 2005;90(5): 685-686.

4. Anderson LJ, Holden S, Davis B, et al. Cardiovascular T2-star (T2*) magnetic resonance for the early diagnosis of myocardial iron overload. Eur Heart J. 2001;22(23):2171-2179.

5. St Pierre TG, Clark PR, Chua-Anusorn W. Measurement and mapping of liver iron concentrations using magnetic resonance imaging. Ann $N$ Y Acad Sci. 2005;1054:379-385.

6. Wood JC, Enriquez C, Ghugre N, et al. MRI R2 and R2* mapping accurately estimates hepatic iron concentration in transfusion-dependent thalassemia and sickle cell disease patients. Blood. 2005; 106(4):1460-1465.

7. Noetzli LJ, Panigrahy A, Mittelman SD, et al. Pituitary iron and volume predict hypogonadism in transfusional iron overload. Am J Hematol. November 4, 2011. [Epub ahead of print.]

8. Wood JC, Noetzl L, Hyderi A, Joukar M, Coates T, Mittelman S. Predicting pituitary iron and endocrine dysfunction. Ann N Y Acad Sci. 2010;1202:123-128.

9. Noetzli LJ, Mittelman SD, Watanabe RM, Coates TD, Wood JC. Pancreatic iron and glucose dysregulation in thalassemia major. $\mathrm{Am} \mathrm{J}$ Hematol. October 20, 2011. [Epub ahead of print.]

10. Breuer W, Shvartsman M, Cabantchik ZI. Intracellular labile iron. Int J Biochem Cell Biol. 2008;40(3):350-354.
11. Cabantchik ZI, Kakhlon O, Epsztejn S, Zanninelli G, Breuer W. Intracellular and extracellular labile iron pools. Adv Exp Med Biol. 2002;509:55-75.

12. Modell B, Khan M, Darlison M, Westwood MA, Ingram D, Pennell DJ. Improved survival of thalassaemia major in the UK and relation to $\mathrm{T} 2 *$ cardiovascular magnetic resonance. J Cardiovasc Magn Reson. 2008;10(1):42.

13. Ladis V, Chouliaras G, Berdoukas V, et al. Survival in a large cohort of Greek patients with transfusion-dependent beta thalassaemia and mortality ratios compared to the general population. Eur J Haematol. 2011;86(4):332-338.

14. Farmaki K, Tzoumari I, Pappa C, Chouliaras G, Berdoukas V. Normalisation of total body iron load with very intensive combined chelation reverses cardiac and endocrine complications of thalassaemia major. Br J Haematol. 2010;148(3):466-475.

15. Cohen AR. New advances in iron chelation therapy. Hematology Am Soc Hematol Educ Program. 2006:42-47.

16. Breuer W, Ghoti H, Shattat A, et al. Non-transferrin bound iron in thalassemia: differential detection of redox active forms in children and older patients. Am J Hematol. 2012;87(1):55-61.

17. Puliyel M, Bush A, Berdoukas V, Hofstra T, Claster S, Mehta B, et al. Trends in ferritin can be dramatically different from trends in total body iron and could lead to erroneous decisions in iron chelation management and discourage adherence in chronically transfused patients. Poster presented at American Society of Hematology Annual General Meeting 2011; San Diego, California.

18. Wood JC. Diagnosis and management of transfusion iron overload: the role of imaging. Am J Hematol. 2007;82(Suppl 12):1132-1135.

19. Piga A, Longo F, Duca L, et al. High nontransferrin bound iron levels and heart disease in thalassemia major. Am J Hematol. 2009;84(1):29-33.

20. Sahlstedt L, von Bonsdorff L, Ebeling F, Parkkinen J, Juvonen E, Ruutu T. Non-transferrin-bound iron in haematological patients during chemotherapy and conditioning for autologous stem cell transplantation. Eur J Haematol. 2009;83(5):455-459.

21. Breuer W, Ronson A, Slotki IN, Abramov A, Hershko C, Cabantchik ZI. The assessment of serum nontransferrin-bound iron in chelation therapy and iron supplementation. Blood. 2000;95(9):2975-2982.

22. Angelucci E, Brittenham GM, McLaren CE, et al. Hepatic iron concentration and total body iron stores in thalassemia major. $N$ Engl J Med. 2000;343(5):327-331.

23. Fischer R, Piga A, Harmatz P, Nielsen P. Monitoring long-term efficacy of iron chelation treatment with biomagnetic liver susceptometry. Ann NY Acad Sci. 2005;1054:350-357.

24. Brittenham GM, Griffith PM, Nienhuis AW, et al. Efficacy of deferoxamine in preventing complications of iron overload in patients with thalassemia major. N Engl J Med. 1994;331(9):567-573.

25. Noetzli LJ, Carson SM, Nord AS, Coates TD, Wood JC. Longitudinal analysis of heart and liver iron in thalassemia major. Blood. 2008;112(7):2973-2978.

26. Piga A, Gaglioti C, Fogliacco E, Tricta F. Comparative effects of deferiprone and deferoxamine on survival and cardiac disease in patients with thalassemia major: a retrospective analysis. Haematologica. 2003;88(5):489-496.

27. Aessopos A, Fragodimitri C, Karabatsos F, et al. Cardiac magnetic resonance imaging R2* assessments and analysis of historical parameters in patients with transfusion-dependent thalassemia. Haematologica. 2007;92(1):131-132.

28. Tanner MA, Galanello R, Dessi C, et al. Myocardial iron loading in patients with thalassemia major on deferoxamine chelation. J Cardiovasc Magn Reson. 2006;8(3):543-547.

29. Borgna-Pignatti C, Vergine G, Lombardo T, et al. Hepatocellular carcinoma in the thalassaemia syndromes. Br J Haematol. 2004;124(1):114-117.

30. Wood JC, Tyszka JM, Carson S, Nelson MD, Coates TD. Myocardial iron loading in transfusion-dependent thalassemia and sickle cell disease. Blood. 2004;103(5):1934-1936.

31. Carpenter JP, He T, Kirk P, et al. On T2* magnetic resonance and cardiac iron. Circulation. 2011;123(14):1519-1528.

32. Kirk P, Roughton M, Porter JB, et al. Cardiac T2* magnetic resonance for prediction of cardiac complications in thalassemia major. Circulation. 2009;120(20):1961-1968. 
33. Sparacia G, Banco A, Midiri M, Iaia A. MR imaging technique for the diagnosis of pituitary iron overload in patients with transfusiondependent beta-thalassemia major. AJNR. 1998;19(10):1905-1907.

34. Lam WW, Au WY, Chu WC, Tam S, Ha SY, Pennell DJ. One-stop measurement of iron deposition in the anterior pituitary, liver, and heart in thalassemia patients. JMRI. 2008;28(1):29-33.

35. Papakonstantinou O, Ladis V, Kostaridou S, et al. The pancreas in beta-thalassemia major: MR imaging features and correlation with iron stores and glucose disturbances. Eur Radiol. 2007;17(6): $1535-1543$

36. Argyropoulou MI, Kiortsis DN, Astrakas L, Metafratzi Z, Chalissos N, Efremidis SC. Liver, bone marrow, pancreas and pituitary gland iron overload in young and adult thalassemic patients: a T2 relaxometry study. Eur Radiol. 2007;17(12):3025-3030.

37. Noetzli LJ, Papudesi J, Coates TD, Wood JC. Pancreatic iron loading predicts cardiac iron loading in thalassemia major. Blood. November 5, 2009;114(19):4021-4026.

38. Au WY, Lam WW, Chu W, et al. A T2* magnetic resonance imaging study of pancreatic iron overload in thalassemia major. Haematologica. 2008;93(1):116-119.

39. Propper RD, Cooper B, Rufo RR, et al. Continuous subcutaenous administration of deferoxamine in patients with iron overload. $N$ Engl J Med. 1977;297(8):418-423.

40. Hussain MA, Green N, Flynn DM, Hussein S, HoffbrandAV. Subcutaneous infusion and intramuscular injection of desferrioxamine in patients with transfusional iron overload. Lancet. 1976;2(7998):1278-1280.

41. Giardina PJ, Grady RW. Chelation therapy in beta-thalassemia: an optimistic update. Semin Hematol. 2001;38(4):360-366.

42. Porter JB, Shah FT. Iron overload in thalassemia and related conditions: therapeutic goals and assessment of response to chelation therapies. Hematol Oncol Clin North Am. 2010;24(6):1109-1130.

43. Wolfe L, Olivieri N, Sallan D, et al. Prevention of cardiac disease by subcutaneous deferoxamine in patients with thalassemia major. $\mathrm{NEngl}$ J Med. 1985;312(25):1600-1603.

44. Freeman AP, Giles RW, Berdoukas VA, Talley PA, Murray IP. Sustained normalization of cardiac function by chelation therapy in thalassaemia major. Clin Lab Haematol. 1989;11(4):299-307.

45. Zurlo MG, De Stefano P, Borgna-Pignatti C, et al. Survival and causes of death in thalassaemia major. Lancet. 1989;2(8653):27-30.

46. Anderson LJ, Westwood MA, Holden S, et al. Myocardial iron clearance during reversal of siderotic cardiomyopathy with intravenous desferrioxamine: a prospective study using $\mathrm{T} 2 *$ cardiovascular magnetic resonance. Br J Haematol. 2004;127(3):348-355.

47. Tamary H, Goshen J, Carmi D, et al. Long-term intravenous deferoxamine treatment for noncompliant transfusion-dependent beta-thalassemia patients. Isr J Med Sci. 1994;30(8):658-664.

48. Piga A, Luzzatto L, Capalbo P, Gambotto S, Tricta F, Gabutti V. Highdose desferrioxamine as a cause of growth failure in thalassemic patients. Eur J Haematol. 1988;40(4):380-381.

49. Orzincolo C, Scutellari PN, Castaldi G. Growth plate injury of the long bones in treated beta-thalassemia. Skeletal Radiol. 1992;21(1): 39-44.

50. Albera R, Pia F, Morra B, et al. Hearing loss and desferrioxamine in homozygous beta-thalassemia. Audiology. 1988;27(4):207-214.

51. Gelmi C, Borgna-Pignatti C, Franchin S, Tacchini M, Trimarchi F. Electroretinographic and visual-evoked potential abnormalities in patients with beta-thalassemia major. Ophthalmologica. 1988;196(1):29-34.

52. Chan GC, Chan S, Ho PL, Ha SY. Effects of chelators (deferoxamine, deferiprone and deferasirox) on the growth of Klebsiella pneumoniae and Aeromonas hydrophila isolated from transfusion-dependent thalassemia patients. Hemoglobin. 2009;33(5):352-360.

53. Chung BH, Ha SY, Chan GC, et al. Klebsiella infection in patients with thalassemia. Clin Infect Dis. 2003;36(5):575-579.

54. Li CK, Shing MM, Chik KW, Lee V, Yuen PM. Klebsiella pneumoniae meningitis in thalassemia major patients. Pediatr Hematol Oncol. 2001;18(3):229-232.
55. Adamkiewicz TV, Berkovitch M, Krishnan C, Polsinelli C, Kermack D, Olivieri NF. Infection due to Yersinia enterocolitica in a series of patients with beta-thalassemia: incidence and predisposing factors. Clin Infect Dis. 1998;27(6):1362-1366.

56. Green NS. Yersinia infections in patients with homozygous betathalassemia associated with iron overload and its treatment. Pediatr Hematol Oncol. 1992;9(3):247-254.

57. Wu SF, Peng CT, Wu KH, Tsai CH. Liver fibrosis and iron levels during long-term deferiprone treatment of thalassemia major patients. Hemoglobin. 2006;30(2):215-218.

58. Chen AC, Peng CT, Wu SF, Wu KH, Chiang IP, Tsai CH. Effect of deferiprone on liver iron overload and fibrosis in hepatitis-C-virusinfected thalassemia. Hemoglobin. 2006;30(2):209-214.

59. Olivieri NF, Brittenham GM, Matsui D, et al. Iron-chelation therapy with oral deferipronein patients with thalassemia major. $N$ Engl J Med. 1995;332(14):918-922.

60. Pennell DJ, Berdoukas V, Karagiorga M, et al. Randomized controlled trial of deferiprone or deferoxamine in beta-thalassemia major patients with asymptomatic myocardial siderosis. Blood. 2006;107(9):3738-3744.

61. Anderson LJ, Wonke B, Prescott E, Holden S, Walker JM, Pennell DJ, Comparison of effects of oral deferiprone and subcutaneous desferrioxamine on myocardial iron concentrations and ventricular function in beta-thalassaemia. Lancet. 2002;360(9332):516-520.

62. Smith GC, Alpendurada F, Carpenter JP, et al. Effect of deferiprone or deferoxamine on right ventricular function in thalassemia major patients with myocardial iron overload. J Cardiovasc Magn Reson. 2011;13:34.

63. Borgna-Pignatti C, Cappellini MD, De Stefano P, et al. Cardiac morbidity and mortality in deferoxamine- or deferiprone-treated patients with thalassemia major. Blood. 2006;107(9):3733-3737.

64. Sohn YS, Breuer W, Munnich A, Cabantchik ZI. Redistribution of accumulated cell iron: a modality of chelation with therapeutic implications. Blood. 2008;111(3):1690-1699.

65. Gao X, Qian M, Campian JL, et al. Mitochondrial dysfunction may explain the cardiomyopathy of chronic iron overload. Free Radic Biol Med. 2010;49(3):401-407.

66. Boddaert N, Le Quan Sang KH, Rotig A, et al. Selective iron chelation in Friedreich ataxia: biologic and clinical implications. Blood. 2007;110(1):401-408.

67. Galanello R. Forest plot of heart disease in patients treated with deferiprone or deferoxamine slides for the September 14, 2011 meeting of the FDA Oncologic Drugs Advisory Committee on Ferriprox (deferiprone). http://www.fda.gov/downloads/ AdvisoryCommittees/CommitteesMeetingMaterials/Drugs/ OncologicDrugsAdvisoryCommittee/UCM275607.pdf.

68. Cohen AR, Galanello R, Piga A, De Sanctis V, Tricta F. Safety and effectiveness of long-term therapy with the oral iron chelator deferiprone. Blood. 2003;102(5):1583-1587.

69. Grady RBV, Rachmielewitz EA, Giardina PJ. Optimising chelation therapy: combining deferiprone and deferoxamine. Blood. 2000; 96:604a.

70. Wonke B, Wright C, Hoffbrand AV. Combined therapy with deferiprone and desferrioxamine. Br J Haematol. 1998;103(2):361-364.

71. Tanner MA, Galanello R, Dessi C, et al. A randomized, placebo-controlled, double-blind trial of the effect of combined therapy with deferoxamine and deferiprone on myocardial iron in thalassemia major using cardiovascular magnetic resonance. Circulation. 2007; 115(14):1876-1884.

72. Tanner MA, Galanello R, Dessi C, et al. Combined chelation therapy in thalassemia major for the treatment of severe myocardial siderosis with left ventricular dysfunction. J Cardiovasc Magn Reson. 2008;10(1):12.

73. Berdoukas V, Chouliaras G, Moraitis P, Zannikos K, Berdoussi E, Ladis V. The efficacy of iron chelator regimes in reducing cardiac and hepatic iron in patients with thalassaemia major: a clinical observational study. J Cardiovasc Magn Reson. 2009;11:20. 
74. Ladis V, Chouliaras G, Berdoukas V, et al. Relation of chelation regimes to cardiac mortality and morbidity in patients with thalassaemia major: an observational study from a large Greek unit. Eur J Haematol. 2010;85(4):335-344.

75. Tsironi M, Deftereos S, Andriopoulos P, Farmakis D, Meletis J, Aessopos A. Reversal of heart failure in thalassemia major by combined chelation therapy: a case report. Eur J Haematol. 2005;74(1): 84-85.

76. Tavecchia L, Masera N, Russo P, et al. Successful recovery of acute hemosiderotic heart failure in beta-thalassemia major treated with a combined regimen of desferrioxamine and deferiprone. Haematologica. 2006;91(Suppl 6):ECR19.

77. Wu KH, Chang JS, Tsai CH, Peng CT. Combined therapy with deferiprone and desferrioxamine successfully regresses severe heart failure in patients with beta-thalassemia major. Ann Hematol. 2004; 83(7):471-473.

78. Cappellini MD, Cohen A, Piga A, et al. A phase 3 study of deferasirox (ICL670), a once-daily oral iron chelator, in patients with beta-thalassemia. Blood. 2006;107(9):3455-3462.

79. Cappellini MD, Taher A. Long-term experience with deferasirox (ICL670), a once-daily oral iron chelator, in the treatment of transfusional iron overload. Expert Opin Pharmacother. 2008;9(13):2391-2402.

80. Cappellini MD, Porter J, El-Beshlawy A, et al. Tailoring iron chelation by iron intake and serum ferritin: the prospective EPIC study of deferasirox in 1744 patients with transfusion-dependent anemias. Haematologica. 2009;95(4):557-566.

81. Taher A, Cappellini MD. Update on the use of deferasirox in the management of iron overload. Ther Clin Risk Manag. 2009;5: 857-868.

82. Taher A, Cappellini MD, Vichinsky E, et al. Efficacy and safety of deferasirox doses of $>30 \mathrm{mg} / \mathrm{kg}$ per d in patients with transfusion-dependent anaemia and iron overload. Br J Haematol. 2009;147(5):752-759.

83. Taher A, El-Beshlawy A, Elalfy MS, et al. Efficacy and safety of deferasirox, an oral iron chelator, in heavily iron-overloaded patients with beta-thalassaemia: the ESCALATOR study. Eur J Haematol. 2009;82(6):458-465

84. Pennell D, Porter JB, Cappellini MD, et al. Deferasirox for up to 3 years leads to continued improvement of myocardial T2* in patients with beta-thalassemia major. Haematologica. 2012;97(6):842-848.

85. Pennell DJ, Porter JB, Cappellini MD, et al. Continued improvement in myocardial $\mathrm{T} 2 *$ over two years of deferasirox therapy in betathalassemia major patients with cardiac iron overload. Haematologica. 2011;96(1):48-54

86. Wood WG, Weatherall DJ, Hart GH, Bennett M, Marsh GW. Hematologic changes and hemoglobin analysis beta thalassemia heterozygotes during the first year of life. Pediatr Res. 1982;16(4 Pt 1): 286-289.

87. Pennell DJ, Porter JB, Cappellini MD, et al. Efficacy of deferasirox in reducing and preventing cardiac iron overload in beta-thalassemia Blood. 2010;115(12):2364-2371.

88. Cappellini MD, Bejaoui M, Agaoglu L, et al. Iron chelation with deferasirox in adult and pediatric patients with thalassemia major: efficacy and safety during 5 years' follow-up. Blood. 2011 Jul 28;118(4):884-93.
89. Jetsrisuparb A, Komvilaisak P, Wiangnon S, Jetsrisuparb C. Retrospective study on the combination of desferrioxamine and deferasirox for treatment of iron-overloaded thalassemic patients: first evidence of more than 2 years. J Pediatr Hematol Oncol. 2010;32(5):400-403.

90. Lal A, Sweeters N, Herz M, Foote D, Neumayr L, Kurio G, et al. Safety of combined chelation therapy with deferasirox and deferoxamine in transfusion-dependent thalassemia. Blood. 2009;114:2021.

91. Farmaki K, Tzoumari I, Pappa C. Oral chelators in transfusiondependent thalassemia major patients may prevent or reverse iron overload complications. Blood Cells Mol Dis. 15;47(1):33-40.

92. Balocco M, Carrara P, Pinto V, Forni GL. Daily alternating deferasirox and deferiprone therapy for "hard-to-chelate" beta-thalassemia major patients. Am J Hematol. 2010;85(6):460-461.

93. Berdoukas V, Carson S, Nord A, et al. Combining two orally active iron chelators for thalassemia. Ann Hematol. 2010;89(11):1177-1178.

94. Esposito BP, Breuer W, Sirankapracha P, Pootrakul P, Hershko C, Cabantchik ZI. Labile plasma iron in iron overload: redox activity and susceptibility to chelation. Blood. 2003;102(7):2670-2677.

95. Daar S, Pathare A, Nick H, et al. Reduction in labile plasma iron during treatment with deferasirox, a once-daily oral iron chelator, in heavily iron-overloaded patients with beta-thalassaemia. Eur J Haematol. 2009;82(6):454-457.

96. Pootrakul P, Breuer W, Sametband M, Sirankapracha P, Hershko C, Cabantchik ZI. Labile plasma iron (LPI) as an indicator of chelatable plasma redox activity in iron-overloaded beta-thalassemia/HbE patients treated with an oral chelator. Blood. 2004;104(5):1504-1510.

97. Walter PB, Macklin EA, Porter J, et al. Inflammation and oxidantstress in beta-thalassemia patients treated with iron chelators deferasirox (ICL670) or deferoxamine: an ancillary study of the Novartis CICL670A0107 trial. Haematologica. 2008;93(6):817-825.

98. Pennell DJ, Carpenter JP, Roughton M, Cabantchik Z. On improvement in ejection fraction with iron chelation in thalassemia major and the risk of future heart failure. J Cardiovasc Magn Reson. 2011;13:45.

99. Wood JC, Glynos T, Thompson A, et al. Follow-up report on the 2-year cardiac data from a deferasirox monotherapy trial. Am J Hematol. 2010;85(10):818-819.

100. Ceci A, Baiardi P, Catapano M, et al. Risk factors for death in patients with beta-thalassemia major: results of a case-control study. Haematologica. 2006;91(10):1420-1421.

101. Telfer PT, Warburton F, Christou S, et al. Improved survival in thalassemia major patients on switching from desferrioxamine to combined chelation therapy with desferrioxamine and deferiprone. Haematologica. 2009;94(12):1777-1778.

102. Maggio A, Vitrano A, Capra M, et al. Improving survival with deferiprone treatment in patients with thalassemia major: a prospective multicenter randomised clinical trial under the auspices of the Italian Society for Thalassemia and Hemoglobinopathies. Blood Cells Mol Dis. 2009;42(3):247-251.
Journal of Blood Medicine

\section{Publish your work in this journal}

The Journal of Blood Medicine is an international, peer-reviewed, open access, online journal publishing laboratory, experimental and clinical aspects of all topics pertaining to blood based medicine including but not limited to: Transfusion Medicine; Blood collection, Donor issues, Transmittable diseases, and Blood banking logistics; Immunohematology; Artificial and alternative

\section{Dovepress}

blood based therapeutics; Hematology; Biotechnology/nanotechnology of blood related medicine; Legal aspects of blood medicine; Historical perspectives. The manuscript management system is completely online and includes a very quick and fair peer-review system. Visit http://www.dovepress.com/ testimonials.php to read real quotes from published authors. 